\title{
A Systematic Review of Minimally Invasive Versus Open Radical Antegrade Modular Pancreatosplenectomy for Pancreatic Cancer
}

\author{
KOSEI TAKAGI, YUZO UMEDA, RYUICHI YOSHIDA, TAKAHITO YAGI and TOSHIYOSHI FUJIWARA \\ Department of Gastroenterological Surgery, Okayama University Graduate School of Medicine, \\ Dentistry, and Pharmaceutical Sciences, Okayama, Japan
}

\begin{abstract}
Background/Aim: The aim of this study was to investigate surgical and oncological outcomes of minimally invasive (MI) and open radical antegrade modular pancreatosplenectomy (RAMPS) for the treatment of left-sided pancreatic cancer. Materials and Methods: A systematic literature search and meta-analyses were performed focusing on short-term surgical oncology of MI- and open-RAMPS. Results: A total of seven studies with 423 patients were included in this review. The equivalent short-term and long-term outcomes of the groups were confirmed. The results of meta-analyses found no significant difference in $R 0$ resection rates $(O R=1.78,95 \% C I=0.76-4.15$, $p=0.18)$, although MI-RAMPS was associated with a smaller number of dissected lymph nodes $(M D=-3.14,95 \% C I=-4.75-$ $-1.53, p<0.001)$ and lymph node metastases (OR=0.55, 95\%CI=0.31-0.97, $p=0.04)$. Conclusion: MI-RAMPS could provide surgically and oncologically feasible outcomes for wellselected left-sided pancreatic cancer as compared to openRAMPS. However, further high-level evidence should be needed to confirm survival benefits following MI-RAMPS.
\end{abstract}

Radical antegrade modular pancreatosplenectomy (RAMPS) is a standardized technique for left-sided pancreatic cancer (1). The feasibility of applying RAMPS to patients with pancreatic cancer has been demonstrated (2-4). In contrast, the evidence of minimally invasive distal pancreatectomy for pancreatic

This article is freely accessible online.

Correspondence to: Kosei Takagi, MD, Ph.D., Department of Gastroenterological Surgery, Okayama University Graduate School of Medicine, Dentistry, and Pharmaceutical Sciences, 2-5-1 Shikatacho, Kita-ku, Okayama 700-8558, Japan. Tel: +81 862237151, Fax: +81862218775, e-mail: kotakagi15@gmail.com

Key Words: Distal pancreatectomy, laparoscopic, pancreatic cancer, radical antegrade modular pancreatosplenectomy, robotic, review. cancer is still lacking despite recent rapid development of minimally invasive pancreas resection (5). This is because that there are several critical issues still under debate with respect to surgical and oncological feasibility of minimally invasive RAMPS (MI-RAMPS) over open RAMPS (open-RAMPS) (6). To date, surgical and oncological feasibility of MI-RAMPS compared to open-RAMPS have not yet been systemically examined in patients with pancreatic cancer.

The aim of this study was to investigate surgical and oncological outcomes of MI-RAMPS in comparison with those of open-RAMPS. Furthermore, meta-analysis was performed focusing on short-term surgical oncology of MIand open-RAMPS for pancreatic cancer.

\section{Materials and Methods}

Search methodology. This study was conducted in accordance with the Preferred Reporting Items for Systematic Reviews and Meta-Analyses (PRISMA) guidelines (7). A systematic search of Pubmed Central, Web of Science, and Cochrane CENTRAL was performed on August $7^{\text {th }}$, 2021, radical antegrade modular pancreatosplenectomy as a key word phrase.

Reports in the English language that compared outcomes of MIand open-RAMPS for pancreatic cancer were included. Reports without abstracts, conference abstracts, and reviews were excluded.

Following the removal of duplicate records, all abstracts were screened independently by two investigators. Next, full-text manuscripts were assessed for eligibility. Extracted data were as follows: year and country of study publication, study design, surgical approach (MI- or open-RAMPS), operative outcomes (operative time and blood loss), pathological outcomes (tumor size, number of dissected lymph nodes and lymph node metastasis, and R0 resection rates), short-term outcomes [postoperative complications, postoperative pancreatic fistula (POPF), and postoperative length of stays], and longterm outcomes (survival and recurrence).

Investigators evaluated the methodologic quality of the studies included in the meta-analysis according to the Newcastle-Ottawa quality assessment scale for cohort studies (8). Studies with a total score of $\leq 5,6-7$, and $\geq 8$ were considered to be of low quality, moderate quality, and high quality, respectively (9). 


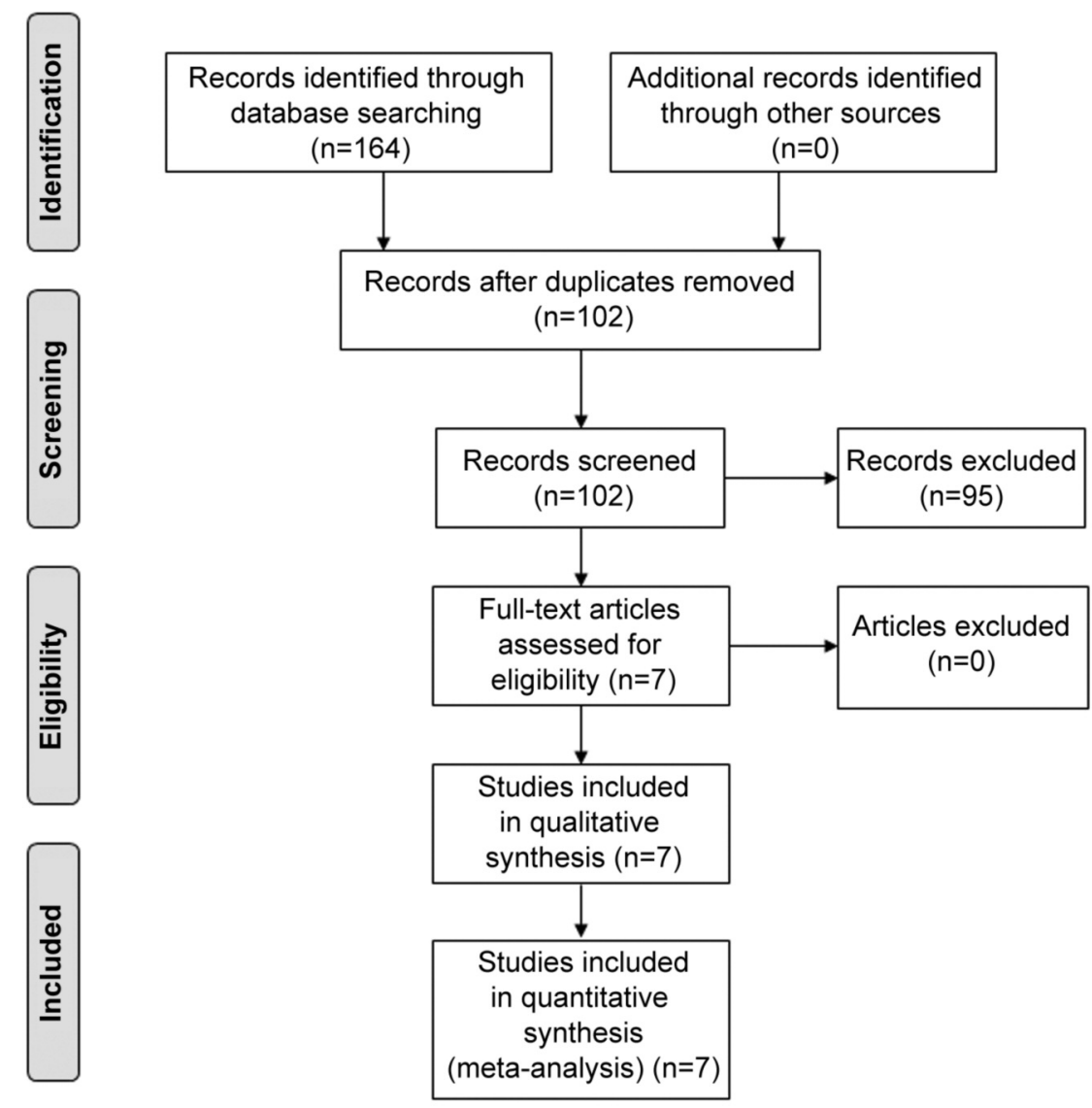

Figure 1. PRISMA 2009 flow diagram.

Statistical analysis. Outcomes were demonstrated as they were presented in original articles in accordance with the defined variables. A meta-analysis was conducted with the use of Review Manager, version 5.3 (the Cochrane Collaboration, 2014). The pooled odds ratio (OR) with corresponding $95 \%$ confidence interval $(95 \% \mathrm{CI})$ for dichotomous variables was calculated with the MantelHaenszel method. The mean difference (MD) for continuous variables was calculated with the inverse variance method. Heterogeneity among studies was analyzed by calculating the $I^{2}$ values and the Chi-square test. A fixed-effects model was used, however, a random-effects model was used in cases with $I^{2}$ values of $40 \%$ or more. Potential publication bias for outcomes was evaluated with visual inspection of the Funnel plots.

\section{Results}

Study characteristics. The PRISMA flow chart in this study is demonstrated in Figure 1. Following removal of duplicate articles and screening full-text articles for eligibility, a total of seven studies (10-16) matched the inclusion criteria. Overall, seven studies with 423 patients were included in the meta-analysis.

A summary of the included studies is demonstrated in Table I. All included studies were single-center retrospective series from Korea $(n=1)$, China $(n=3)$, Japan $(n=2)$, and Italy $(n=1)$.
Out of 423 patients, there were 145 undergoing MI-RAMPS and 278 with open-RAMPS. With regards to indication of MIRAMPS for pancreatic cancer, the Yonsei criteria were commonly introduced for selecting patients $(10,12)$. In general, tumors involving major vessels, such as the portal vein and celiac trunk, should be excluded from the indication for MI-RAMPS. However, Rosso et al. (13) reported the feasibility of MI-RAMPS with vascular resection. The methodologic quality of the studies included was evaluated to be of low quality for three studies $(13,15,16)$, and moderate quality for four studies $(10-12,14)$.

Operative and pathological outcomes in the included studies are summarized in Table II. The average operative time was approximately 324 minutes for MI-RAMPS, and 293 minutes for open-RAMPS. The estimated blood loss was approximately $271 \mathrm{ml}$ for MI-RAMPS and $447 \mathrm{ml}$ for openRAMPS. Out of all pathological outcomes, all of the included studies reported R0 resection rates of $95.2 \%$ for the MI-RAMPS group and $88.8 \%$ for the open-RAMPS group.

The results of postoperative short- and long-term outcomes between the MI- and open-RAMPS groups are depicted in Table III. The MI-RAMPS group had an overall 
Table I. Published studies reporting on outcomes of minimally invasive versus open radical antegrade modular pancreatosplenectomy for pancreatic cancer.

\begin{tabular}{|c|c|c|c|c|c|c|}
\hline Study (Year) & Country & $\begin{array}{l}\text { Study } \\
\text { design }\end{array}$ & $\begin{array}{l}\text { No. of } \\
\text { patients }\end{array}$ & $\begin{array}{l}\text { Details of } \\
\text { MIS }\end{array}$ & $\begin{array}{l}\text { Indication of MIS for } \\
\text { pancreatic cancer }\end{array}$ & Quality ${ }^{\dagger}$ \\
\hline $\begin{array}{l}\text { Lee } \text { et al. } \\
\text { (2014) (10) }\end{array}$ & Korea & $\begin{array}{l}\text { Retrospective, } \\
\text { single center }\end{array}$ & $\begin{array}{l}\text { MIS }(n=12) \\
\text { Open }(n=78)\end{array}$ & $\begin{array}{l}\text { Laparoscopic } \\
\text { or robotic }\end{array}$ & $\begin{array}{l}\text { Yonsei criteria: } \\
\text { 1) Tumor confirmed to the pancreas } \\
\text { 2) Intact fascia layer between the distal } \\
\text { pancreas and the left adrenal gland and kidney } \\
\text { 3) Tumor located at least } 1-2 \mathrm{~cm} \text { away } \\
\text { from the celiac axis }\end{array}$ & 7 \\
\hline $\begin{array}{l}\text { Zhang et al. } \\
\text { (2017) (11) }\end{array}$ & China & $\begin{array}{l}\text { Retrospective, } \\
\text { single center }\end{array}$ & $\begin{array}{l}\text { MIS }(n=22) \\
\text { Open }(n=76)\end{array}$ & Laparoscopic & N.A. & 6 \\
\hline $\begin{array}{l}\text { Kawabata et al. } \\
(2020)(12)\end{array}$ & Japan & $\begin{array}{l}\text { Retrospective, } \\
\text { single center }\end{array}$ & $\begin{array}{l}\text { MIS }(n=30) \\
\text { Open }(n=33)\end{array}$ & Laparoscopic & Yonsei criteria & 7 \\
\hline $\begin{array}{l}\text { Rosso et al. } \\
(2020) \text { (13) }\end{array}$ & Italy & $\begin{array}{l}\text { Retrospective, } \\
\text { single center }\end{array}$ & $\begin{array}{l}\text { MIS }(n=17) \\
\text { Open }(n=6)\end{array}$ & Laparoscopic & $\begin{array}{l}\text { Critical points for vascular resection: } \\
\text { 1) the length of venous involvement } \\
\text { 2) the presence of splenic artery and } \\
\text { celiac trunk involvement } \\
\text { 3) the need to preserve the } \\
\text { pancreatic-duodenal veins } \\
\text { Exclusion criteria: } \\
\text { 1) simultaneous venous and arterial invasion } \\
\text { 2) portal vein stricture with portal hypertension }\end{array}$ & 5 \\
\hline $\begin{array}{l}\text { Zhang et al. } \\
\text { (2020) (14) }\end{array}$ & China & $\begin{array}{l}\text { Retrospective, } \\
\text { single center }\end{array}$ & $\begin{array}{l}\text { MIS }(n=25) \\
\text { Open }(n=23)\end{array}$ & Laparoscopic & N.A. & 6 \\
\hline $\begin{array}{l}\text { Huang et al. } \\
\text { (2021) (15) }\end{array}$ & China & $\begin{array}{l}\text { Retrospective, } \\
\text { single center }\end{array}$ & $\begin{array}{l}\text { MIS }(n=20) \\
\text { Open }(n=31)\end{array}$ & Laparoscopic & N.A. & 5 \\
\hline $\begin{array}{l}\text { Hirashita et al. } \\
(2021)(16)\end{array}$ & Japan & $\begin{array}{l}\text { Retrospective, } \\
\text { single center }\end{array}$ & $\begin{array}{l}\text { MIS }(n=19) \\
\text { Open }(n=31)\end{array}$ & Laparoscopic & $\begin{array}{l}\text { Exclusion criteria: } \\
\text { Major vessel invasions, including the portal vein, } \\
\text { superior mesenteric artery, and celiac artery. }\end{array}$ & 5 \\
\hline
\end{tabular}

$\dagger$ A total score of 9 evaluated by the Newcastle-Ottawa quality assessment scale for cohort studies (8). MIS: Minimally invasive surgery; N.A.: not available.

complication rate of $24 \%$, and a POPF rate (grade $\mathrm{B} / \mathrm{C}$ ) of $14 \%$. The rates of overall complications and POPF were $32 \%$ and $13.3 \%$, respectively, in the open-RAMPS group. No mortality following MI-RAMPS was reported.

Regarding long-term outcomes following MI- and openRAMPS, only one study [Lee et al. (10)] reported a 5-year overall survival showing a significantly longer survival in MIRAMPS compared to open-RAMPS (55.6\% versus $30.0 \%$, $p=0.02$ ). However, other studies demonstrated no significant differences in overall survival as well as recurrence-free survival between the groups. Zhang et al. (11) showed a mean overall survival of 29.6 months for the MI-RAMPS group and 27.6 months for the open-RAMPS group $(p=0.34)$. A study by Kawabata et al. (12) found no significant differences in overall $(p=0.82)$ and recurrence-free $(p=0.31)$ survival between the groups. Another study [Zhang et al. (14)] presented a median overall and disease-free survival of 24.5 and 18.1 months, respectively, for MI-RAMPS, with no significant differences compared to open-RAMPS. In a study by Huang et al. (15), the survival rates at 1 year and 2 years were not statistically different between the MI- and open-RAMPS groups $(67.0 \%$ versus $78.0 \%$ and $50.2 \%$ versus $39.3 \% ; p=0.41$ ). Hirashita et al. (16) showed no significant differences in overall $(p=0.40)$ and recurrence-free $(p=0.08)$ survival between the groups.

Meta-analysis of MI-versus open-RAMPS.

Operative outcomes. Meta-analyses including five studies demonstrated significantly longer operative time $(\mathrm{MD}=30.0$, $\left.95 \% \mathrm{CI}=7.58-52.4, \quad p=0.009, I^{2}=44 \%, \mathrm{n}=337\right)$, but less estimated blood loss (MD=-163, 95\%CI=-293--33.4, $p=0.01$, $\left.I^{2}=77 \%, \mathrm{n}=337\right)$ with MI-RAMPS compared to open-RAMPS (Figure 2A and B).

Pathological outcomes. Meta-analyses found significant associations between MI- and open-RAMPS in terms of tumor size $\left(\mathrm{MD}=-0.62,95 \% \mathrm{CI}=-1.01--0.23, p=0.002, I^{2}=0 \%\right.$, $\mathrm{n}=337$ ), number of dissected lymph nodes ( $\mathrm{MD}=-3.14$, $\left.95 \% \mathrm{CI}=-4.75--1.53, p<0.001, I^{2}=0 \%, \mathrm{n}=337\right)$, and lymph node metastasis $\left(\mathrm{OR}=0.55,95 \% \mathrm{CI}=0.31-0.97, p=0.04, I^{2}=0 \%\right.$, $\mathrm{n}=312$ ) (Figure 2C, D and E). In contrast, no significant difference was found in the $\mathrm{R} 0$ resection rates between the groups $\left(\mathrm{OR}=1.78,95 \% \mathrm{CI}=0.76-4.15, p=0.18, I^{2}=0 \%, \mathrm{n}=423\right)$, as shown in Figure $2 \mathrm{~F}$. The results were homogeneous for pathological outcomes. 
Table II. Operative and pathological outcomes of minimally invasive versus open radical antegrade modular pancreatosplenectomy for pancreatic cancer.

\begin{tabular}{|c|c|c|c|c|c|c|c|}
\hline Study & Procedure & $\begin{array}{l}\text { Operative } \\
\text { time (min) }\end{array}$ & $\begin{array}{l}\text { Blood loss } \\
\quad(\mathrm{ml})\end{array}$ & $\begin{array}{l}\text { Tumor size } \\
\quad(\mathrm{cm})\end{array}$ & $\begin{array}{l}\text { Dissected } \\
\text { LN }\end{array}$ & $\begin{array}{c}\mathrm{LN} \text { metastasis } \\
(\%)\end{array}$ & $\begin{array}{c}\text { R0 resection } \\
(\%)\end{array}$ \\
\hline \multirow[t]{2}{*}{ Lee et al. (10) } & MIS (n=12) & $324.3(154.2)$ & $445.8(346.1)$ & $2.8(1.3)$ & $10.5(7.1)$ & $3(25)$ & $12(100)$ \\
\hline & Open $(n=78)$ & $270.1(140.4)$ & $669.5(776.1)$ & $3.5(1.9)$ & $13.8(11.1)$ & $37(47.4)$ & $67(85.9)$ \\
\hline \multirow[t]{2}{*}{ Zhang et al. (11) } & MIS (n=22) & $188(39)$ & $210(130)$ & $3.6(1.3)$ & $11.2(4.6)$ & $8(36)$ & $20(91)$ \\
\hline & Open $(n=76)$ & $160(35)$ & $240(120)$ & $4.4(1.4)$ & $14.4(5.5)$ & $31(41)$ & $66(87)$ \\
\hline \multirow[t]{2}{*}{ Kawabata et al. (12) } & MIS (n=30) & $389(280-576)$ & $18(0-180)$ & $2.3(0.4-8.3)$ & $18(5-51)$ & N.A. & $29(96.7)$ \\
\hline & Open $(n=33)$ & $382(256-674)$ & $215(30-1,030)$ & $2.0(0.4-4.1)$ & $25(7-80)$ & & $30(90.9)$ \\
\hline \multirow[t]{2}{*}{ Rosso et al. (13) } & MIS ( $\mathrm{n}=17)$ & $395-412$ & N.A. & N.A. & $30-35$ & $15(88)$ & $17(100)$ \\
\hline & Open $(n=6)$ & 450 & & & 37 & $6(100)$ & $6(100)$ \\
\hline \multirow[t]{2}{*}{ Zhang et al. (14) } & MIS (n=25) & $212.2(66.3)$ & $402(258.8)$ & $3.7(1.7)$ & $15.8(6.7)$ & N.A. & $23(92)$ \\
\hline & Open $(n=23)$ & $203.1(39.7)$ & $506.5(418.4)$ & $4.4(2.0)$ & $18.2(8.0)$ & & $21(91)$ \\
\hline \multirow[t]{2}{*}{ Huang et al. (15) } & MIS $(n=20)$ & $273.8(90.3)$ & $252.5(198.3)$ & $4.2(1.9)$ & $9.6(6.4)$ & $6(30)$ & $20(100)$ \\
\hline & Open $(n=31)$ & $264.3(77.1)$ & $472.6(428)$ & $4.2(1.6)$ & $12.8(5.8)$ & $12(39)$ & $30(97)$ \\
\hline \multirow{2}{*}{ Hirashita et al. (16) } & MIS (n=19) & $397(78)$ & $299(237)$ & $2.8(2.3)$ & $14(17)$ & $5(26)$ & $17(89)$ \\
\hline & Open $(n=31)$ & $319(80)$ & $576(78)$ & $3.4(1.8)$ & $19(18)$ & $16(52)$ & 27 (97) \\
\hline
\end{tabular}

Values are indicated as mean (standard deviation), or median (range). LN: Lymph node; MIS: minimally invasive surgery; N.A.: not available.

Table III. Postoperative short- and long-term outcomes of minimally invasive versus open radical antegrade modular pancreatosplenectomy for pancreatic cancer.

\begin{tabular}{|c|c|c|c|c|c|c|}
\hline Study & Procedure & Complication (\%) & POPF (\%) & Mortality (\%) & LOS (days) & Survival (MIS vs. open) \\
\hline \multirow[t]{2}{*}{ Lee et al. (10) } & MIS (n=12) & Overall: 3 (25) & Grade B/C: $0(0)$ & $0(0)$ & $12.3(6.8)$ & 5-year OS (\%): \\
\hline & Open $(n=78)$ & $29(37.2)$ & $8(10.3)$ & $2(2.6)$ & $22.4(21.6)$ & 55.6 vs. $30.0(p=0.024)$ \\
\hline \multirow[t]{2}{*}{ Zhang et al. (11) } & MIS (n=22) & N.A. & Grade B/C: 2 (9.1) & $0(0)$ & N.A. & Mean OS (months): \\
\hline & Open $(n=76)$ & & $7(9.2)$ & $0(0)$ & & $\begin{array}{c}29.6(3.7) v s . \\
27.6(2.1)(p=0.34)\end{array}$ \\
\hline \multirow[t]{2}{*}{ Kawabata et al. (12) } & $\operatorname{MIS}(n=30)$ & Overall: 4 (13.3) & Grade B/C: 1 (3.3) & $0(0)$ & $14(8-67)$ & 2-year OS (\%): \\
\hline & Open $(n=33)$ & $6(18.2)$ & $2(6.1)$ & $0(0)$ & $16(8-96)$ & $\begin{array}{c}90.9 \text { vs. } 78.9(p=0.82) \\
2 \text {-year RFS }(\%): \\
92.9 \text { vs. } 62.5(p=0.31)\end{array}$ \\
\hline \multirow[t]{2}{*}{ Rosso et al. (13) } & MIS (n=17) & Overall: 9 (52.9) & Overall: 3 (17.6) & $0(0)$ & N.A. & N.A. \\
\hline & Open $(n=6)$ & $3(50)$ & $2(14.7)$ & $0(0)$ & & \\
\hline \multirow[t]{3}{*}{ Zhang et al. (14) } & MIS (n=25) & Overall: 4 (16) & Overall: 2 (8) & $0(0)$ & $11.7(5.2)$ & Median OS (months): \\
\hline & Open $(n=23)$ & $3(13)$ & $0(0)$ & $0(0)$ & $12.9(5.0)$ & 24.5 vs. $28.7(p=0.63)$ \\
\hline & & & & & & $\begin{array}{c}\text { Median DFS: } \\
18.1 v s .20 .0(p=0.99)\end{array}$ \\
\hline \multirow[t]{2}{*}{ Huang et al. (15) } & MIS (n=20) & Overall: 5 (25) & Grade B/C: 9 (45) & $0(0)$ & $19(9.9)$ & 2-year OS $(\%)$ : \\
\hline & Open $(n=31)$ & $13(41.9)$ & $10(32.3)$ & $0(0)$ & $19.6(16.8)$ & 50.2 vs. $38.3(p=0.41)$ \\
\hline \multirow[t]{2}{*}{ Hirashita et al. (16) } & MIS (n=19) & N.A. & Grade B/C: 2 (11) & $0(0)$ & $21.5(10.5)$ & OS: N.S. $(p=0.40)$ \\
\hline & Open $(n=31)$ & & $6(19)$ & $0(0)$ & $29.4(23.3)$ & RFS: N.S. $(p=0.08)$ \\
\hline
\end{tabular}

Values are indicated as mean (standard deviation), or median (range). POPF: Postoperative pancreatic fistula; LOS: length of stay; MIS: minimally invasive surgery; OS: overall survival; RFS: relapse/recurrence-free survival; DFS: disease-free survival; N.A.: not available; N.S.: not statistically different.

Short-term outcomes. Meta-analyses indicated no significant differences in MI- and open-RAMPS regarding the overall complication rate $(\mathrm{OR}=0.69,95 \% \mathrm{CI}=0.36-1.30, p=0.25$, $I^{2}=0 \%, \mathrm{n}=275 ;$ Figure $3 \mathrm{~A}$ ), POPF (grade $\mathrm{B}$ and $\mathrm{C}$ ) $\left(\mathrm{OR}=0.91,95 \% \mathrm{CI}=0.44-1.88, \quad p=0.79, \quad I^{2}=0 \%, \mathrm{n}=352\right.$; Figure $3 \mathrm{~B}$ ), and the postoperative length of hospital stay $\left(\mathrm{MD}=-1.94,95 \% \mathrm{CI}=-4.48-0.59, p=0.13, I^{2}=11 \%, \mathrm{n}=239\right.$;
Figure 3C). No significant heterogeneity was found across the studies included.

Publication bias. Funnel plots demonstrated no obvious asymmetry regarding the number of dissected lymph nodes and lymph node metastases, and R0 resection, as shown in Figure 4. 


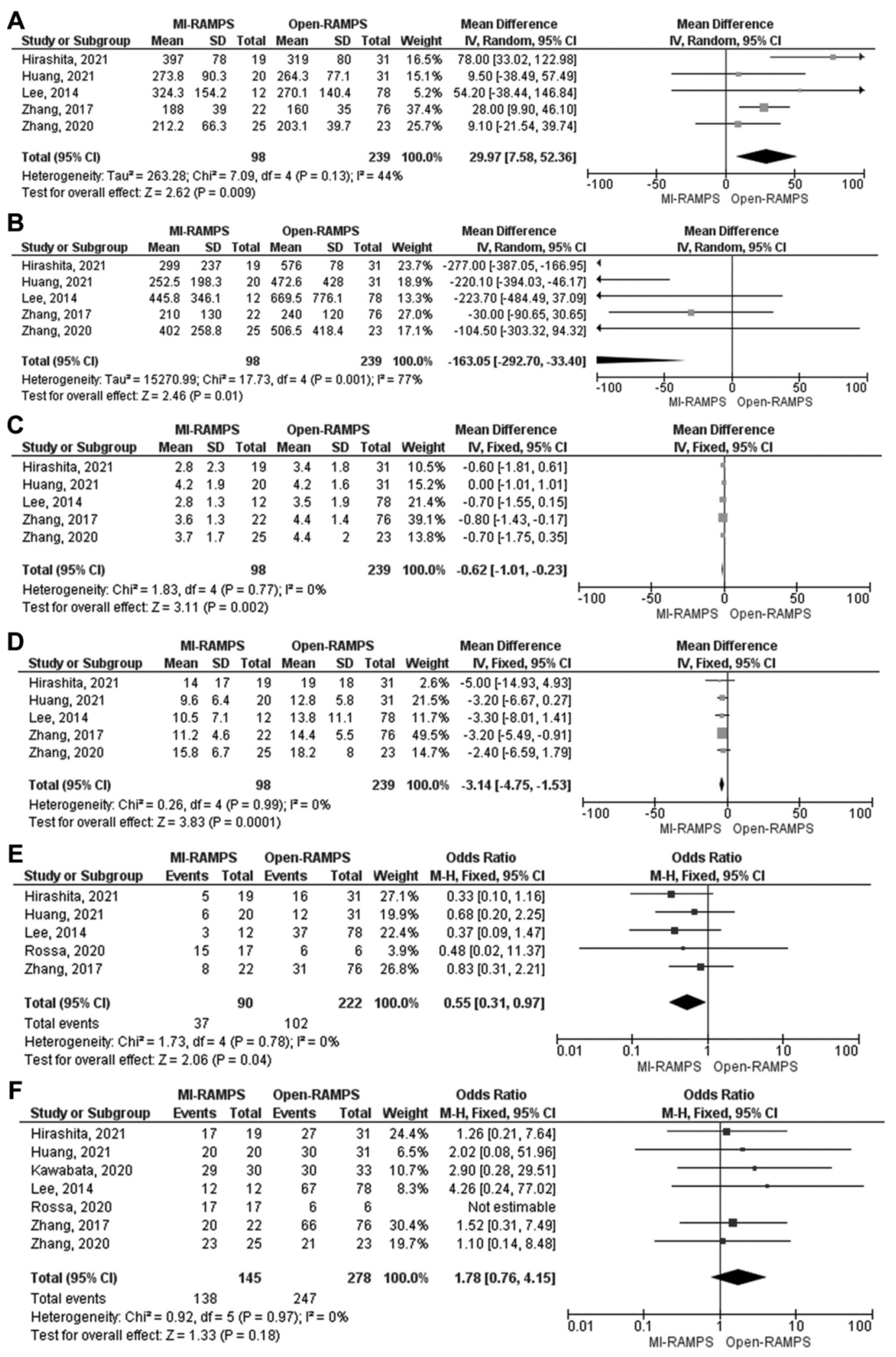

Figure 2. The results of the meta-analysis demonstrating operative and pathological outcomes in terms of minimally invasive-versus open-radical antegrade modular pancreatosplenectomy. (A) Operative time; (B) blood loss; (C) tumor size; (D) number of dissected lymph nodes; (E) number of lymph node metastases; and $(F)$ RO resection. 
A

MI-RAMPS Open-RAMPS

Odds Ratio

Odds Ratio

Study or Subgroup Events Total Events Total Weight $\mathrm{M}-\mathrm{H}$, Fixed, $95 \% \mathrm{Cl}$

M-H, Fixed, $95 \% \mathrm{Cl}$

$\begin{array}{lrrrrrr}\text { Huang, 2021 } & 5 & 20 & 13 & 31 & 33.1 \% & 0.46[0.13,1.59] \\ \text { Kawabata, 2020 } & 4 & 30 & 6 & 33 & 21.4 \% & 0.69[0.18,2.74] \\ \text { Lee, 2014 } & 3 & 12 & 29 & 78 & 25.1 \% & 0.56[0.14,2.25] \\ \text { Rossa, 2020 } & 9 & 17 & 3 & 6 & 9.0 \% & 1.13[0.17,7.24] \\ \text { Zhang, 2020 } & 4 & 25 & 3 & 23 & 11.4 \% & 1.27[0.25,6.40] \\ \text { Total (95\% Cl) } & & & & & & \\ \text { Total events } & 25 & & 54 & & & \end{array}$

Heterogeneity: $\mathrm{Chi}^{2}=1.30, \mathrm{df}=4(\mathrm{P}=0.86) ; \mathrm{I}^{2}=0 \%$

Test for overall effect: $Z=1.15(P=0.25)$

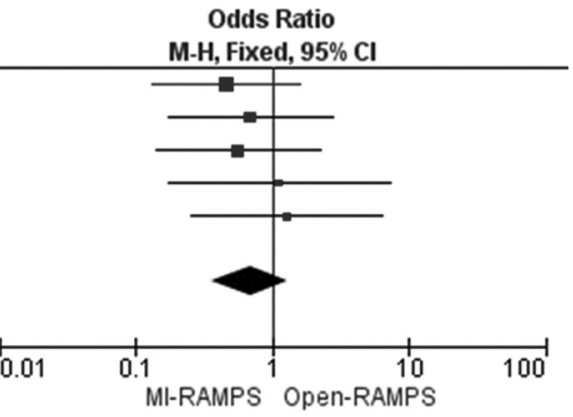

B

\begin{tabular}{|c|c|c|c|c|c|c|c|c|c|c|}
\hline \multirow[b]{2}{*}{ Study or Subgroup } & \multicolumn{2}{|c|}{ MI-RAMPS } & \multicolumn{2}{|c|}{ Open-RAMPS } & \multirow[b]{2}{*}{ Weight } & \multirow{2}{*}{$\begin{array}{c}\text { Odds Ratio } \\
\text { M-H, Fixed, 95\% Cl }\end{array}$} & \multirow{2}{*}{\multicolumn{4}{|c|}{$\begin{array}{c}\text { Odds Ratio } \\
\text { M-H, Fixed, } 95 \% \mathrm{Cl}\end{array}$}} \\
\hline & Events & Total & Events & Total & & & & & & \\
\hline Hirashita, 2021 & 2 & 19 & 6 & 31 & $26.5 \%$ & $0.49[0.09,2.72]$ & & & & \\
\hline Huang, 2021 & 9 & 20 & 10 & 31 & $28.0 \%$ & $1.72[0.54,5.48]$ & & & & \\
\hline Kawabata, 2020 & 1 & 30 & 2 & 33 & $12.0 \%$ & $0.53[0.05,6.21]$ & & & & \\
\hline Lee, 2014 & 0 & 12 & 8 & 78 & $15.0 \%$ & $0.33[0.02,6.12]$ & & & & \\
\hline Zhang, 2017 & 2 & 22 & 7 & 76 & $18.6 \%$ & $0.99[0.19,5.12]$ & & & & \\
\hline Total $(95 \% \mathrm{CI})$ & & 103 & & 249 & $100.0 \%$ & $0.91[0.44,1.88]$ & & & & \\
\hline Total events & 14 & & 33 & & & & & & & \\
\hline $\begin{array}{l}\text { Heterogeneity: } \mathrm{Chi}^{2} \\
\text { Test for overall effect }\end{array}$ & $\begin{array}{l}2.31, d f= \\
Z=0.26\end{array}$ & $\begin{array}{l}4(P=0 \\
P=0.7\end{array}$ & $\begin{array}{l}\text { 0.68); } 1^{2}= \\
9)\end{array}$ & & & & 0.01 & 0.1 MI-RAMPS & Open-RAN & $\begin{array}{l}10 \\
\text { MPS }\end{array}$ \\
\hline
\end{tabular}

C

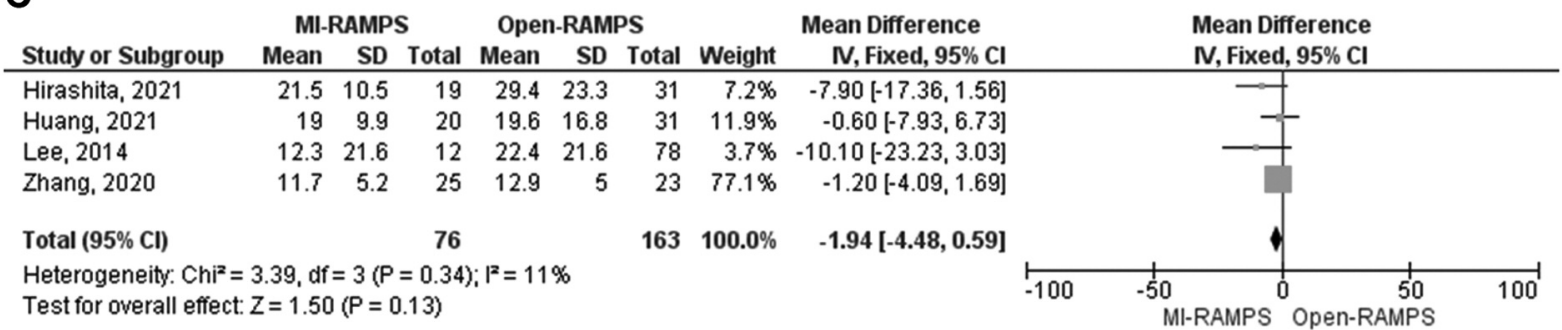

Figure 3. The results of the meta-analysis demonstrating short-term outcomes in terms of minimally invasive-versus open-radical antegrade modular pancreatosplenectomy. (A) Overall complications; (B) postoperative pancreatic fistula; and $(C)$ postoperative length of hospital stay.

\section{Discussion}

The present study summarized the current evidence on MI- and open-RAMPS in patients with pancreatic cancer. To the best of our knowledge, this is the first study to investigate surgical and oncological outcomes following MI-RAMPS in comparison with those following open-RAMPS. The results of meta-analyses found favorable surgical and oncological outcomes following MI-RAMPS for well-selected left-sided pancreatic cancer.

RAMPS enables early vascular control, improved visualization of the proper posterior dissection line, and higher lymph node dissection and negative tangential margin rates (17). Furthermore, meta-analyses have shown that RAMPS is associated with higher R0 resection rates and a greater number of dissected lymph nodes as compared to the standard distal pancreatectomy (2-4). However, high-level evidence to support a survival benefit following RAMPS is still lacking. With respect to MI-RAMPS, a recent systematic review, including eight studies with 92 cases, demonstrated technical feasibility and oncologically acceptable outcomes for the treatment of pancreatic cancer (6). To date, however, there are no published meta-analyses that compare surgical and oncological outcomes of MI- and open-RAMPS.

The results of this meta-analysis indicated that the MIRAMPS group had a significantly smaller number of dissected lymph nodes and lymph node metastases. However, no statistically significant difference was found in terms of R0 resection rates. In addition, comparable postoperative short-term outcomes were confirmed between the groups. Regarding longterm outcomes following MI- and open-RAMPS, equivalent overall and recurrence-free survival have been reported. Among several oncological factors, R0 resection rate is known as an important factor that should be achieved to improve survival following surgery for pancreatic cancer $(18,19)$. It is also 

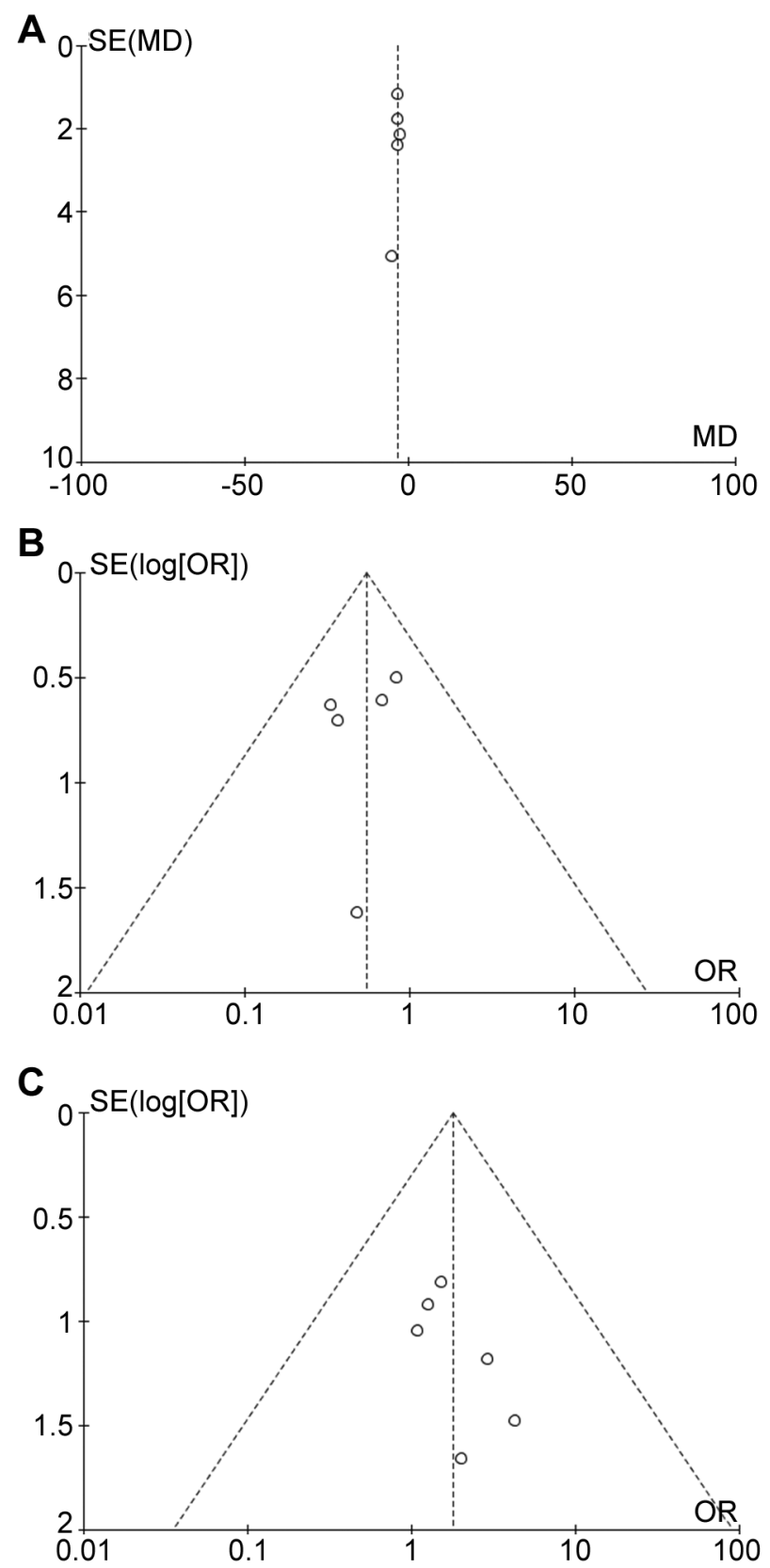

Figure 4. Funnel plots demonstrating pathological outcomes in terms of minimally invasive- versus open-radical antegrade modular pancreatosplenectomy. (A) number of dissected lymph nodes; (B) number of lymph node metastases; and $(C)$ RO resection.

important to understand the risk factors for postoperative longterm outcomes after curative resection in determining the indication of MI- and open-RAMPS (20,21).

Several limitations are associated with the present study. Firstly, all the included studies were retrospective series with relatively small sample sizes. The number of included studies in the meta-analysis was also small. The results could be affected by a publication bias. Secondly, meta-analyses were performed focusing on short-term surgical oncology outcomes in pancreatic cancer, but not for long-term outcomes due to limited data. Therefore, further studies should be conducted to investigate survival benefits following MI- and open-RAMPS for pancreatic cancer. Thirdly, various surgical techniques for MI-RAMPS were reported (6). Moreover, evidence on robotic RAMPS for pancreatic cancer is still lacking. Robotic surgery with improved three-dimensional visualization and flexible manipulation should overcome technical difficulties of the medial approach in laparoscopic RAMPS $(22,23)$.

\section{Conclusion}

The present study suggests that MI-RAMPS could provide surgically and oncologically feasible outcomes for wellselected left-sided pancreatic cancer as compared to openRAMPS. Further investigations are needed to confirm survival benefits following MI-RAMPS. Last but not least, well-designed studies with larger sample sizes should be performed to prove the significance of MI-RAMPS.

\section{Conflicts of Interest}

The Authors declare no conflicts of interest regarding this study.

\section{Authors' Contributions}

K.T. contributed to the study conception and design, the acquisition of data, the development of the protocol, and the drafting of the manuscript. Y.U. and R.Y. contributed to the analysis and interpretation of the results and the revision of the final draft. T.Y. and T.F. contributed to the development of the protocol and the critical revision of the final draft. All Authors have approved the final version.

\section{Acknowledgements}

Financial support was received from the Japan Society for the Promotion of Science (Tokyo, Japan, grant number 21K16447).

\section{References}

1 Strasberg SM, Drebin JA and Linehan D: Radical antegrade modular pancreatosplenectomy. Surgery 133(5): 521-527, 2003. PMID: 12773980. DOI: 10.1067/msy.2003.146

2 Zhou Q, Fengwei-Gao, Gong J, Xie Q, Liu Y, Wang Q and Lei $\mathrm{Z}$ : Assessement of postoperative long-term survival quality and complications associated with radical antegrade modular pancreatosplenectomy and distal pancreatectomy: a metaanalysis and systematic review. BMC Surg 19(1): 12, 2019. PMID: 30691444. DOI: 10.1186/s12893-019-0476-x

3 Cao F, Li J, Li A and Li F: Radical antegrade modular pancreatosplenectomy versus standard procedure in the treatment of left-sided pancreatic cancer: A systemic review and metaanalysis. BMC Surg 17(1): 67, 2017. PMID: 28583142. DOI: 10.1186/s12893-017-0259-1 
4 Zhou Y, Shi B, Wu L and Si X: A systematic review of radical antegrade modular pancreatosplenectomy for adenocarcinoma of the body and tail of the pancreas. HPB (Oxford) 19(1): 10-15, 2017. PMID: 27553838. DOI: 10.1016/j.hpb.2016.07.014

5 Asbun HJ, Moekotte AL, Vissers FL, Kunzler F, Cipriani F, Alseidi A, D’Angelica MI, Balduzzi A, Bassi C, Björnsson B, Boggi U, Callery MP, Del Chiaro M, Coimbra FJ, Conrad C, Cook A, Coppola A, Dervenis C, Dokmak S, Edil BH, Edwin B, Giulianotti PC, Han HS, Hansen PD, van der Heijde N, van Hilst J, Hester CA, Hogg ME, Jarufe N, Jeyarajah DR, Keck T, Kim SC, Khatkov IE, Kokudo N, Kooby DA, Korrel M, de Leon FJ, Lluis N, Lof S, Machado MA, Demartines N, Martinie JB, Merchant NB, Molenaar IQ, Moravek C, Mou YP, Nakamura M, Nealon WH, Palanivelu C, Pessaux P, Pitt HA, Polanco PM, Primrose JN, Rawashdeh A, Sanford DE, Senthilnathan P, Shrikhande SV, Stauffer JA, Takaori K, Talamonti MS, Tang CN, Vollmer CM, Wakabayashi G, Walsh RM, Wang SE, Zinner MJ, Wolfgang CL, Zureikat AH, Zwart MJ, Conlon KC, Kendrick ML, Zeh HJ, Hilal MA, Besselink MG and International Study Group on Minimally Invasive Pancreas Surgery (I-MIPS): The Miami International evidence-based guidelines on minimally invasive pancreas resection. Ann Surg 271(1): 1-14, 2020. PMID: 31567509. DOI: 10.1097/SLA.0000000000003590

6 Larkins K, Rowcroft A, Pandanaboyana S and Loveday BPT: A systematic scoping review of the initial experience with laparoscopic radical antegrade modular pancreatosplenectomy for pancreatic malignancy. Surg Endosc 35(9): 4930-4944, 2021. PMID: 33988769. DOI: 10.1007/s00464-021-08528-5

7 Moher D, Liberati A, Tetzlaff J, Altman DG and PRISMA Group: Preferred reporting items for systematic reviews and meta-analyses: the PRISMA statement. BMJ 339: b2535, 2009. PMID: 19622551. DOI: 10.1136/bmj.b2535

8 Wells G SB, O'Connell D, Peterson J, Welch V. Wells G, Shea B, O'Connell D, Peterson J, Welch V, Losos M and Tugwell P: The Newcastle-Ottawa Scale (NOS) for assessing the quality of nonrandomized studies in meta-analysis. Available at: www.ohri.ca/programs/clinical_epidemiology/oxford.asp [Last accessed on December 6, 2021]

9 Takagi K, Domagala P, Polak WG, Buettner S and Ijzermans JNM: The controlling nutritional status score and postoperative complication risk in gastrointestinal and hepatopancreatobiliary surgical oncology: a systematic review and meta-analysis. Ann Nutr Metab 74(4): 303-312, 2019. PMID: 31013491. DOI: $10.1159 / 000500233$

10 Lee SH, Kang CM, Hwang HK, Choi SH, Lee WJ and Chi HS: Minimally invasive RAMPS in well-selected left-sided pancreatic cancer within Yonsei criteria: long-term (>median 3 years) oncologic outcomes. Surg Endosc 28(10): 28482855, 2014. PMID: 24853839. DOI: 10.1007/s00464-0143537-3

11 Zhang AB, Wang Y, Hu C, Shen Y and Zheng SS: Laparoscopic versus open distal pancreatectomy for pancreatic ductal adenocarcinoma: a single-center experience. J Zhejiang Univ Sci B 18(6): 532-538, 2017. PMID: 28585429. DOI: 10.1631/jzus. B1600541

12 Kawabata Y, Hayashi H, Kaji S, Fujii Y, Nishi T and Tajima Y: Laparoscopic versus open radical antegrade modular pancreatosplenectomy with artery-first approach in pancreatic cancer. Langenbecks Arch Surg 405(5): 647-656, 2020. PMID: 32524466. DOI: $10.1007 / \mathrm{s} 00423-020-01887-\mathrm{y}$
13 Rosso E, Frey S, Zimmitti G, Manzoni A, Garatti M and Iannelli A: Laparoscopic radical antegrade modular pancreatosplenectomy with vascular resection for pancreatic cancer: tips and tricks. J Gastrointest Surg 24(12): 2896-2902, 2020. PMID: 32666495. DOI: 10.1007/s11605-020-04695-3

14 Zhang H, Li Y, Liao Q, Xing C, Ding C, Zhang T, Guo J, Han X, Xu Q, Wu W, Zhao Y and Dai M: Comparison of minimal invasive versus open radical antegrade modular pancreatosplenectomy (RAMPS) for pancreatic ductal adenocarcinoma: a single center retrospective study. Surg Endosc 35(7): 3763-3773, 2021. PMID: 33033915. DOI: 10.1007/s00464-020-07938-1

15 Huang J, Xiong C, Sheng Y, Zhou X, Lu CD and Cai X: Laparoscopic versus open radical antegrade modular pancreatosplenectomy for pancreatic cancer: a single-institution comparative study. Gland Surg 10(3): 1057-1066, 2021. PMID: 33842250. DOI: $10.21037 / \mathrm{gs}-21-56$

16 Hirashita T, Iwashita Y, Fujinaga A, Nakanuma H, Tada K, Masuda T, Endo Y, Ohta $\mathrm{M}$ and Inomata $\mathrm{M}$ : Surgical and oncological outcomes of laparoscopic versus open radical antegrade modular pancreatosplenectomy for pancreatic ductal adenocarcinoma. Surg Today, 2021. PMID: 34173053. DOI: 10.1007/s00595-021-02326-1

17 Chun YS: Role of radical antegrade modular pancreatosplenectomy (RAMPS) and pancreatic cancer. Ann Surg Oncol 25(1): 46-50, 2018. PMID: 27848048. DOI: 10.1245/s10434-016-5675-4

18 Nagakawa Y, Nakagawa N, Takishita C, Uyama I, Kozono S, Osakabe H, Suzuki K, Nakagawa N, Hosokawa Y, Shirota T, Honda M, Yamada T, Katsumata $\mathrm{K}$ and Tsuchida A: Reconsideration of the appropriate dissection range based on japanese anatomical classification for resectable pancreatic head cancer in the era of multimodal treatment. Cancers (Basel) 13(14): 3605, 2021. PMID: 34298818. DOI: 10.3390/cancers13143605

19 Lai CC, Wang SY, Liao CH, Hsu JT, Chiang KC, Yeh TS, Hwang TL and Yeh CN: Surgical margin status of patients with pancreatic ductal adenocarcinoma undergoing surgery with radical intent: risk factors for the survival impact of positive margins. In Vivo 32(6): 1591-1597, 2018. PMID: 30348721. DOI: 10.21873 /invivo.11419

20 Hsu CP, Lee LY, Hsu JT, Hsu YP, Wu YT, Wang SY, Yeh CN, Chen TC and Hwang TL: CD44 predicts early recurrence in pancreatic cancer patients undergoing radical surgery. In Vivo 32(6): 15331540, 2018. PMID: 30348713. DOI: 10.21873/invivo.11411

21 Vujic J, Marsoner K, Wienerroither V, Mischinger HJ and Kornprat P: The predictive value of the CRP-to-albumin ratio for patients with pancreatic cancer after curative resection: a retrospective single center study. In Vivo 33(6): 2071-2078, 2019. PMID: 31662540 . DOI: 10.21873 /invivo.11706

22 Takagi K, Umeda Y, Yoshida R, Yagi T and Fujiwara T: Robotic radical antegrade modular pancreatosplenectomy using the supracolic anterior superior mesenteric artery approach. J Gastrointest Surg 25(11): 3015-3018, 2021. PMID: 34382155. DOI: $10.1007 / \mathrm{s} 11605-021-05112-\mathrm{z}$

23 Liu Q, Zhao G, Zhao Z, Zhang X, Gao Y, Tan X and Liu R: The standardized technique in robotic radical antegrade modular pancreatosplenectomy using the flip-up approach. Langenbecks Arch Surg 406(5): 1697-1703, 2021. PMID: 33585959. DOI: 10.1007/s00423-021-02113-z

Received November 23, 2021

Revised December 7, 2021

Accepted December 8, 2021 